\title{
BMJ Open Burnout prevalence in New Zealand's public hospital senior medical workforce: a cross-sectional mixed methods study
}

\author{
Charlotte N L Chambers, ${ }^{1}$ Christopher M A Frampton, ${ }^{2}$ Murray Barclay, ${ }^{2}$ \\ Martin $\mathrm{McKee}^{3}$
}

To cite: Chambers CNL, Frampton CMA, Barclay M, et al. Burnout prevalence in New Zealand's public hospital senior medical workforce: a cross-sectional mixed methods study. BMJ Open 2016;6:e013947. doi:10.1136/bmjopen-2016013947

- Prepublication history for this paper is available online. To view these files please visit the journal online (http://dx.doi.org/10.1136/ bmjopen-2016-013947).

Received 25 August 2016 Revised 11 October 2016 Accepted 25 October 2016

CrossMark

\footnotetext{
${ }^{1}$ Association of Salaried Medical Specialists, Wellington, New Zealand ${ }^{2}$ University of Otago, Christchurch, New Zealand ${ }^{3}$ London School of Hygiene and Tropical Medicine, London, UK
}

Correspondence to Dr Charlotte N L Chambers; CC@asms.nz

\section{ABSTRACT}

Objectives: To explore the prevalence of, and associated factors contributing to burnout among senior doctors and dentists working in the New Zealand's public health system.

Design: Cross-sectional, mixed methods study. Setting: New Zealand's 20 district health boards (DHBs).

Participants: A total of 1487 of 3740 senior doctors and dentists who are members of the Association of Salaried Medical Specialists working in DHBs were recruited (response rate 40\%).

Primary and secondary outcome measures: Gender, age, self-rated health status, vocation and hours of work per week were obtained from an electronic questionnaire. Burnout was measured using the Copenhagen Burnout Inventory. Qualitative data taken from an open-ended comments section was coded using grounded theory and used for contextual data.

Results: The overall prevalence of high personal burnout was $50 \%$. Women aged $<40$ years had $71 \%$ prevalence of high personal burnout. Prevalence of high work-related burnout and patient-related burnout was $42 \%$ and $16 \%$, respectively. Those working in emergency medicine and psychiatry had significantly higher mean work-related burnout than other specialties $(p<0.001)$. On multivariate analysis, having fair or poor health status $(\mathrm{OR} 10.8,95 \% \mathrm{Cl} 6.8$ to 17.1), working more than 14 consecutive hours (OR $1.43,95 \% \mathrm{Cl} 1.12$ to 1.82 ) and being a woman (OR $2.14,95 \% \mathrm{Cl} 1.68$ to 2.73 ) were independently associated with high personal and work-related burnout. Personal burnout rates decreased with age (age 30-39 OR 2.86, 95\% Cl 1.78 to 4.59, age 40-49 OR $2.45,95 \%$ Cl 1.70 to 3.55 , age 50-59 OR 1.70 , $95 \% \mathrm{Cl} 1.17$ to 2.46 , compared with age $>60$ ). Qualitative data emphasised intense and unrelenting workloads, under-staffing, onerous on-call duties and frustrations with management as factors contributing to burnout.

Conclusions: High burnout appears prevalent in New Zealand's senior doctors and dentists. Many attribute their feelings of burnout to work conditions. These findings may assist with understanding contributors to

\section{Strengths and limitations of this study}

- This is the first study to report levels of burnout through the Copenhagen Burnout Inventory in a multispecialty nationwide survey of senior doctors and dentists in any country and offers an approach that could be emulated elsewhere.

- Consideration of the qualitative data alongside the statistical results provides insight into recurring factors perceived as contributing to feelings of burnout.

- The limitations of this study include a moderate participation rate, self-reported data and the cross-sectional design with its limitation of causal inference.

burnout and with developing strategies to ameliorate the high burnout found across this cohort.

\section{INTRODUCTION}

The medical workforce is deemed particularly prone to burnout due to the stressful and emotionally demanding nature of healthcare provision and typically unrelenting high workloads. Existing research suggests that doctors are very susceptible to burnout and have higher rates of burnout when compared with the general public. ${ }^{1}$ Connections have been made between doctor's propensity for burnout and long hours of work, ${ }^{2}$ presenteeism, ${ }^{3}$ shift work and on-call duties. ${ }^{4-6}$

Burnout is of concern for doctors because of the risk it poses to the health of those afflicted $^{78}$ and the loss of highly skilled professionals from the workforce ${ }^{9} 10$ and also because of known correlations between burnout and reduced quality of care ${ }^{11-13}$ and the risk of medical errors. ${ }^{14}{ }^{15}$ Understanding and addressing high levels of burnout in 
doctors is likely to provide opportunities for improving the well-being of this critical workforce as well as enhancing the quality of patient care.

To the best of our knowledge, no studies to date have screened for burnout specifically in senior doctors and dentists using the CBI in a multispecialty, multicentre nationwide survey. This study addresses this gap and aims to assess the prevalence of burnout in senior doctors and dentists of different medical specialties working in New Zealand's public health system. A secondary aim of this research was to better understand which factors were perceived as contributing to burnout in this workforce. By combining qualitative and quantitative findings, this research captures both the levels and correlates of the mental health and well-being of senior doctors and dentists working in New Zealand's public health system and some of the mechanisms through which they are affected. In this way it offers pointers to actions that could potentially improve the psychosocial health of this critical medical workforce.

\section{METHODS}

\section{Participants and study design}

The study involved members of the Association of Salaried Medical Specialists (ASMS) who are medical and dental specialists, and other non-specialist registered medical officers, employed by District Health Boards (DHBs). DHBs provide inpatient and outpatient healthcare for geographically defined populations within the New Zealand's health system and are the main employers of health professionals working in the public sector. The ASMS is the professional association and union for senior doctors and dentists in New Zealand. For ease of description, these ASMS members are referred to throughout this report as senior doctors or as the senior medical workforce. The entire population of DHB-based members of ASMS (3740 individuals) were invited by email to participate voluntarily in an anonymous electronic survey in November 2015. The survey was open for 1-month. 1487 participants completed the survey giving a response rate of $40 \%$. At the time of the survey the ASMS represented over $90 \%$ of all senior doctors and dentists and other non-vocationally registered medical specialists employed within the New Zealand's public health system.

\section{Burnout}

The survey used the Copenhagen Burnout Inventory (CBI) developed by Danish researchers Borritz and Kristensen. ${ }^{16}$ While the Maslach Burnout Inventory (MBI) remains the most commonly used tool to screen for burnout, it has been subject to a number of criticisms, including correlations between emotional exhaustion, depersonalisation and personal accomplishment scales; the fact that it is only available commercially and its applicability to different cultural and workplace contexts. ${ }^{16}{ }^{17}$ In contrast to the more commonly used MBI, the CBI attempts to simplify the concept of burnout to a state of emotional and physical exhaustion. This primary state of 'personal' burnout can then be ascribed to either work-related factors or specifically to work with clients, or in this research context, patients. ${ }^{16} 18$ The CBI questionnaire contains 19 items, each scored on a five-item Likert-scale, with items collapsed into three subscales, relating to personal, work-related and patientrelated burnout. Only those with direct face-to-face contact with patients were invited to participate in the patient-related burnout section. Those who score equal to or above 50 on average in each of the three subscales are scored according to the instructions in the CBI as experiencing a high level of burnout. Prevalence scores are calculated by assessing the percentage of these individuals who score as 'burnt-out' (scores $\geq 50$ ) as a percentage of the overall respondents within each subscale. Mean burnout scores for each subscale are calculated by averaging the scores for each line of questioning and calculating an overall average of the score. ${ }^{16}$

\section{Independent variables}

Additional questions were based on the Australian Medical Association's Risk Assessment checklist for hours of work, including whether or not participants had worked more than 24 consecutive hours, and whether or not they have a period of rest of $<10$ hours. ${ }^{19}$ Respondents were asked to estimate total hours of work for the week prior to completing the survey. Hours of work was defined as standard hours worked, private work, hours on-call (including time on-call but not called in) and any time spent doing administrative tasks at home including email. Independent variables were taken from responses to the WHO's self-health assessment tool and demographic data including gender, age, length of time worked in New Zealand, full time equivalent (FTE) (a formalised measure of employed weekly hours of work where 1 FTE is equal to 40 hours of work), primary DHB and medical specialty. Medical specialties were allocated to 11 broad categories to aid statistical analysis.

\section{Statistical analysis}

Data from the three CBI subscales were analysed for internal and criterion-related validity using Cronbach's $\alpha$ and interitem and item-total correlations. Demographic data including gender, age, length of time working in New Zealand, specialty and place of work were summarised and described. Associations between the mean and prevalence scores on the three burnout scales, hours of work, responses to the risk assessment checklist questions and the independent variables specified above were tested using Spearman's $r, \chi^{2}$ and one-way analysis of variance as appropriate with SPSS (V.23.0). Variables showing significant univariate associations with high level burnout were entered into forward and backward stepwise logistic regressions to determine the presence of significant independent associations. These results are summarised using ORs and 95\% CIs. 


\section{Qualitative data analysis}

Data from the comments section were imported into NVivo pro (V.11), read through in detail and open coded. This initial coding resulted in 41 detailed recurring themes emerging from the comments material. The qualitative data were subsequently re-read and selectively re-coded into five nested macrothemes and subthemes by examining connections between themes and considering how frequently the themes were expressed. This process followed the broad tenets of grounded theory where qualitative data is organised into emergent themes through iterative coding with the resultant themes understood to reflect the perspectives of the research participants. ${ }^{20}$ Patterns arising from the correlation analysis in the quantitative data were also explored by cross-cutting the comments left by respondents according to key variables: gender, age-group and selected specialties with high burnout scores. This crosscut qualitative material was further re-read and re-coded according to the revised macrothemes and subthemes, and comparative analysis was performed between categories of comments to examine whether there were any differences in how themes were expressed or the frequency of thematic expression. Comments selected for inclusion were those that best expressed the various themes. Comments were transcribed directly, and where sections were omitted, ellipses ('...') were used to signify the break. Any words replaced or altered to preserve anonymity or correct for tense or sense are noted within square brackets ('[ ]').

\section{RESULTS}

The demographic composition, work and specialty details of the research participants are summarised in table 1 . The gender and DHB profile of the participants were a close match with the gender and DHB spread of the total ASMS membership; a $\chi^{2}$ goodness of fit test did not show any significant difference between the observed and expected numbers $(49.8, \mathrm{p}=0.096)$. Most participants were men $(59.8 \%)$, aged between 40 and $49(39.1 \%)$ and had worked in New Zealand for $15-30$ years $(44.2 \%)$. The mean hours of work for the respondents of the week immediately prior to completing the survey was 61.5 hours per week. The hours of private work were low (mean 5.3 hours per week) and on average most worked full time (mean FTE 0.9).

\section{Rates of burnout}

The questionnaire's reliability was assessed by Cronbach's $\alpha$ for each dimension, with resulting scores of $0.89,0.89$ and 0.87 for personal, work-related and patient-related burnout, respectively, indicating that items within the three scales were well correlated. The mean burnout scores were strongly correlated $(\mathrm{p}<0.001)$ with correlation coefficients $r_{s} 0.820$ for personal and work burnout, $\mathrm{r}_{\mathrm{s}} 0.451$ for patient and personal burnout
Table 1 Demographic characteristics of respondents $(n=1487)$

\begin{tabular}{llll}
\hline Gender & $\mathbf{n}$ & $\begin{array}{l}\text { Per } \\
\text { cent }\end{array}$ & $\begin{array}{l}\text { Total ASMS } \\
\text { members }\end{array}$ \\
\hline Male & 857 & 59.8 & 2433 \\
Female & 575 & 40.2 & 1407 \\
Age group (years) & & & \\
$\quad 20-29$ & 3 & 0.2 & \\
$30-39$ & 164 & 11.4 & \\
$40-49$ & 563 & 39.1 & \\
$50-59$ & 500 & 34.7 & \\
$>60$ & 211 & 14.6 &
\end{tabular}

Years worked in New Zealand

$\begin{array}{lll}<5 \text { years } & 144 & 10.0\end{array}$

$5-14$ years $\quad 493 \quad 34.2$

15-30 years $\quad 637 \quad 44.2$

$\begin{array}{lll}>30 \text { years } & 167 & 11.6\end{array}$

Self-rated health status

Excellent $\quad 308 \quad 21.0$

Very good $\quad 595 \quad 40.6$

Good $\quad 401 \quad 27.4$

$\begin{array}{lll}\text { Fair } & 142 \quad 9.7\end{array}$

$\begin{array}{lll}\text { Poor } & 18 & 1.2\end{array}$

$\begin{array}{lll}\text { Medical specialty } & & \\ \text { Anaesthesia } & 163 & 11.4\end{array}$

Dentistry $\quad 32 \quad 2.2$

Diagnostic and $\quad 73 \quad 5.1$

interventional

radiology

\begin{tabular}{lll} 
Emergency medicine & 102 & 7.1 \\
General practice & 11 & 0.8 \\
Internal medicine & 441 & 30.8 \\
Obstetrics/ & 61 & 4.3 \\
gynaecology & & \\
Paediatrics & 137 & 9.6 \\
Pathology & 45 & 3.1 \\
Psychiatry & 197 & 13.8 \\
Surgery & 168 & 11.7 \\
\hline
\end{tabular}

\section{Hours of work in week} prior to survey

Total hours worked $61.5 \quad 0-168$

Private hours worked $5.3 \quad 0-100$

Full time equivalent $\quad 0.9 \quad 0.2-1.7$

(FTE)

\begin{tabular}{lll}
$\begin{array}{l}\text { 24-break free of } \\
\text { scheduled work }\end{array}$ & $\mathbf{n}$ & $\begin{array}{l}\text { Per } \\
\text { cent }\end{array}$ \\
\hline $\begin{array}{l}\text { Yes } \\
\text { No }\end{array}$ & 981 & 67.0 \\
\hline $\begin{array}{l}\text { Period of rest between } \\
\text { work of <10 hours }\end{array}$ & $\mathbf{n}$ & $\begin{array}{l}\text { Per } \\
\text { cent }\end{array}$ \\
\hline \multicolumn{1}{r}{ Yes } & 680 & 46.9 \\
$\quad$ No & 771 & 53.1 \\
\hline Worked more than 14 & & \\
consecutive hours & $\mathbf{n}$ & $\%$ \\
\hline$\quad$ Yes & 683 & 46.6 \\
$\quad$ No & 784 & 53.4 \\
\hline
\end{tabular}


Table 2 Mean burnout scores across three subscales and demographic variables

\begin{tabular}{|c|c|c|c|c|c|c|c|c|c|}
\hline \multirow{2}{*}{$\frac{\text { Variable }}{\text { Gender }}$} & \multicolumn{3}{|c|}{ Personal burnout } & \multicolumn{3}{|c|}{ Work-related burnout } & \multicolumn{3}{|c|}{ Patient-related burnout } \\
\hline & Mean & SD & $p<0.001$ & Mean & SD & $\mathrm{p}<0.001$ & Mean & SD & $p=0.395$ \\
\hline Female & 51.4 & 16.7 & & 47.1 & 18.4 & & 29.9 & 17.5 & \\
\hline Male & 45.1 & 17.6 & & 42.7 & 19.1 & & 29.0 & 18.1 & \\
\hline Self-rated health status & Mean & SD & $\mathrm{p}<0.001$ & Mean & SD & $p<0.001$ & Mean & SD & $p<0.001$ \\
\hline Excellent & 36.6 & 16.7 & & 34.7 & 18.0 & & 24.1 & 16.6 & \\
\hline Very good & 44.6 & 15.3 & & 41.5 & 17.2 & & 27.8 & 16.9 & \\
\hline Good & 53.8 & 14.2 & & 49.4 & 16.6 & & 32.4 & 17.3 & \\
\hline Fair & 63.4 & 15.5 & & 60.5 & 18.1 & & 38.6 & 21.6 & \\
\hline Poor & 70.1 & 17.6 & & 63.1 & 19.6 & & 30.9 & 17.6 & \\
\hline Years worked in NZ & Mean & $\mathrm{SD}$ & $\mathrm{p}<0.001$ & Mean & $\mathrm{SD}$ & $\mathrm{p}<0.001$ & Mean & $\mathrm{SD}$ & $p=0.409$ \\
\hline$<5$ years & 47.8 & 17.6 & & 43.8 & 19.2 & & 25.5 & 18.8 & \\
\hline $5-14$ years & 49.9 & 17.1 & & 46.7 & 19.0 & & 29.6 & 17.9 & \\
\hline $15-30$ years & 47.7 & 17.3 & & 45.0 & 18.4 & & 31.2 & 17.7 & \\
\hline$>30$ years & 40.4 & 17.5 & & 36.3 & 18.4 & & 25.5 & 16.8 & \\
\hline Age group (years) & Mean & SD & $p<0.001$ & Mean & SD & $p<0.001$ & Mean & SD & $p=0.485$ \\
\hline 20-29 & 50.0 & 15.0 & & 46.4 & 6.2 & & 23.6 & 21.4 & \\
\hline 30-39 & 53.0 & 17.4 & & 47.6 & 17.8 & & 28.6 & 18.0 & \\
\hline $40-49$ & 49.9 & 17.0 & & 46.2 & 18.8 & & 29.6 & 17.6 & \\
\hline $50-59$ & 46.7 & 16.5 & & 44.6 & 18.8 & & 30.4 & 18.1 & \\
\hline 60 or over & 39.8 & 18.6 & & 36.9 & 19.0 & & 27.2 & 18.0 & \\
\hline Medical specialty & Mean & SD & $p=0.173$ & Mean & SD & $\mathrm{p}<0.001$ & Mean & SD & $p<0.001$ \\
\hline Anaesthesia & 44.7 & 16.3 & & 40.0 & 16.5 & & 24.4 & 16.2 & \\
\hline Dentistry & 47.7 & 14.6 & & 47.0 & 16.9 & & 32.8 & 16.4 & \\
\hline Diagnostic and interventional radiology & 49.8 & 14.9 & & 44.8 & 16.2 & & 23.8 & 14.0 & \\
\hline Emergency medicine & 50.2 & 15.6 & & 51.3 & 18.1 & & 32.7 & 17.7 & \\
\hline General practice & 39.8 & 19.4 & & 33.4 & 21.7 & & 27.3 & 19.2 & \\
\hline Internal medicine & 47.7 & 18.1 & & 44.1 & 19.8 & & 29.2 & 17.8 & \\
\hline Obstetrics/gynaecology & 47.1 & 18.3 & & 42.7 & 20.3 & & 24.6 & 16.2 & \\
\hline Paediatrics & 46.7 & 16.5 & & 41.1 & 17.5 & & 29.2 & 18.4 & \\
\hline Pathology & 50.5 & 19.3 & & 45.6 & 19.0 & & 25.4 & 13.6 & \\
\hline Psychiatry & 49.5 & 17.6 & & 48.1 & 19.0 & & 35.9 & 18.6 & \\
\hline Surgery & 46.1 & 19.0 & & 44.3 & 19.5 & & 28.1 & 18.0 & \\
\hline
\end{tabular}

and $r_{s} 0.556$ for work and patient-related burnout. Table 2 displays the differences in mean burnout scores according to the variables recorded.

Proportionately, $50.1 \%$ of the respondents were identified as having high personal burnout, $42.1 \%$ with high work-related burnout and $15.7 \%$ with high burnout attributed to interactions with patients. Female respondents were significantly more burnt-out than their male counterparts for personal and work-related burnout. About $59.4 \%$ of women scored as having high personal burnout and $46.9 \%$ with high work-related burnout compared with $43.9 \%$ and $39 \%$ of men, respectively $(\mathrm{p}<0.001$ and $\mathrm{p}=0.003)$. Female respondents in the 30-39 year age bracket $(n=88)$ had very high prevalence of personal burnout $(70.5 \%)$.

Those with a longer length of time working in the New Zealand's public health system had significantly lower mean burnout scores for personal and work-related burnout. Those aged between 30 and 39 years $(n=164)$ had the highest mean personal burnout scores with the burnout scores decreasing with age (Figure 1). Mean burnout scores across all three subscales were significantly associated with worsening self-rated health status.
There were significant associations between specialty and mean work-related and patient-related burnout. Those working in emergency medicine and psychiatry had the highest mean work-related burnout scores and those working in psychiatry and dentistry had the highest mean patient-related burnout scores. Figure 2 displays the mean work-related burnout by personal burnout by specialty.

There were significant correlations between the total hours of work recorded by participants and mean personal and work-related burnout scores $\left(r_{s}=0.098\right.$, $\mathrm{p}<0.001, \mathrm{r}=0.125, \mathrm{p}<0.001$ respectively). There was a weak negative correlation $\left(r_{s}-0.060, p=0.021\right)$ between the hours of private work and the personal burnout subscale score. There was no association between the FTE of the respondent and any of the mean burnout subscales although there was a weak association between the mean FTE and the proportion of those scoring as burntout in the work-related subscale $(\mathrm{p}=0.035)$. Working more than 14 hours during the past week was significantly associated with higher mean personal and workrelated burnout $(\mathrm{p}<0.001)$. On a proportionate basis, the same trend held for personal and work-related 


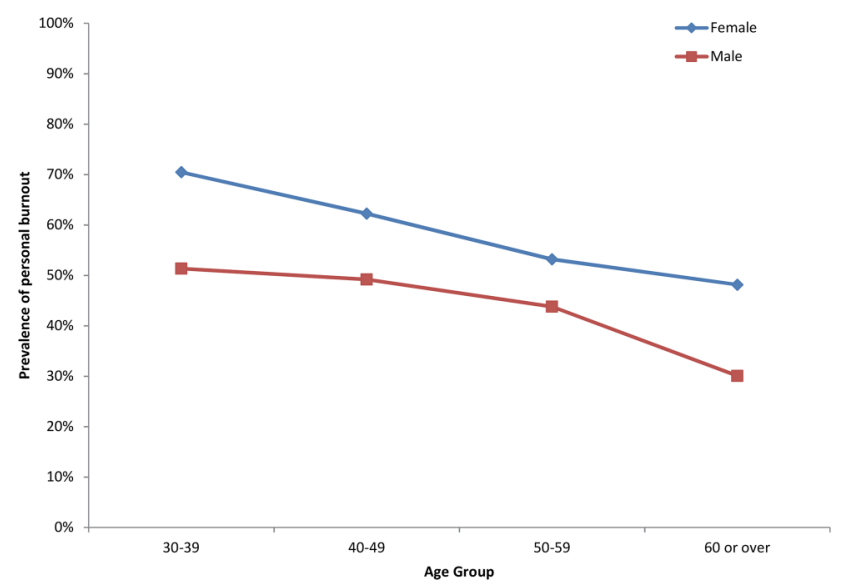

Figure 1 Prevalence of personal burnout (\%) by gender and age group.

burnout $(\mathrm{p}=0.003$ and $\mathrm{p}<0.001$ respectively). Not having had 24 hours free of work during the past week was strongly associated with higher mean personal and workrelated burnout scores $(\mathrm{p}<0.001)$. There was no association between the burnout scores across the subscales and whether or not the respondent had a period of rest of $<10$ hours in the past week.

\section{Independent factors associated with burnout}

As detailed in table 3, a logistic regression demonstrated that those whose self-rated health status was fair or poor (grouped) had the highest OR for burnout across all three burnout categories compared to those who self- rated their health as either very good or excellent (grouped). Those aged younger than 60 years had a much higher risk of burnout, than those aged over 60 years (reference group). Being a woman had an OR of 2.1 for personal burnout and 1.5 for work-related burnout $(p=0.001)$ compared with men. Working greater hours was a risk factor across both personal and work-related burnout but working more than 14 hours consecutively was only a risk factor for work-related burnout (OR 1.4 compared with not working 14 consecutive hours, $\mathrm{p}=0.004)$.

\section{Qualitative findings: perceptions of factors relating to burnout}

Table 4 details macro themes drawn from the comments section of the survey with illustrative comments. Unless explicitly stated, all are from different individual respondents. A total of 752 respondents provided comments for qualitative analysis (51\% of the total respondents). Many described their perceptions of the most frustrating, tiring and stress-inducing factors associated with their work. Some sought to explain their recorded hours of work over the week, and many reacted strongly to the final section of the CBI which focused on burnout as a consequence of interactions with patients. Many rejected the implied assertion that patients were a source of their burnout, instead noting that "[it's] more frustrating working with administration than patients". Others reacted to the lack of questions that tapped into what they found the most frustrating and burnout-inducing elements of their work, for example, "you have failed to

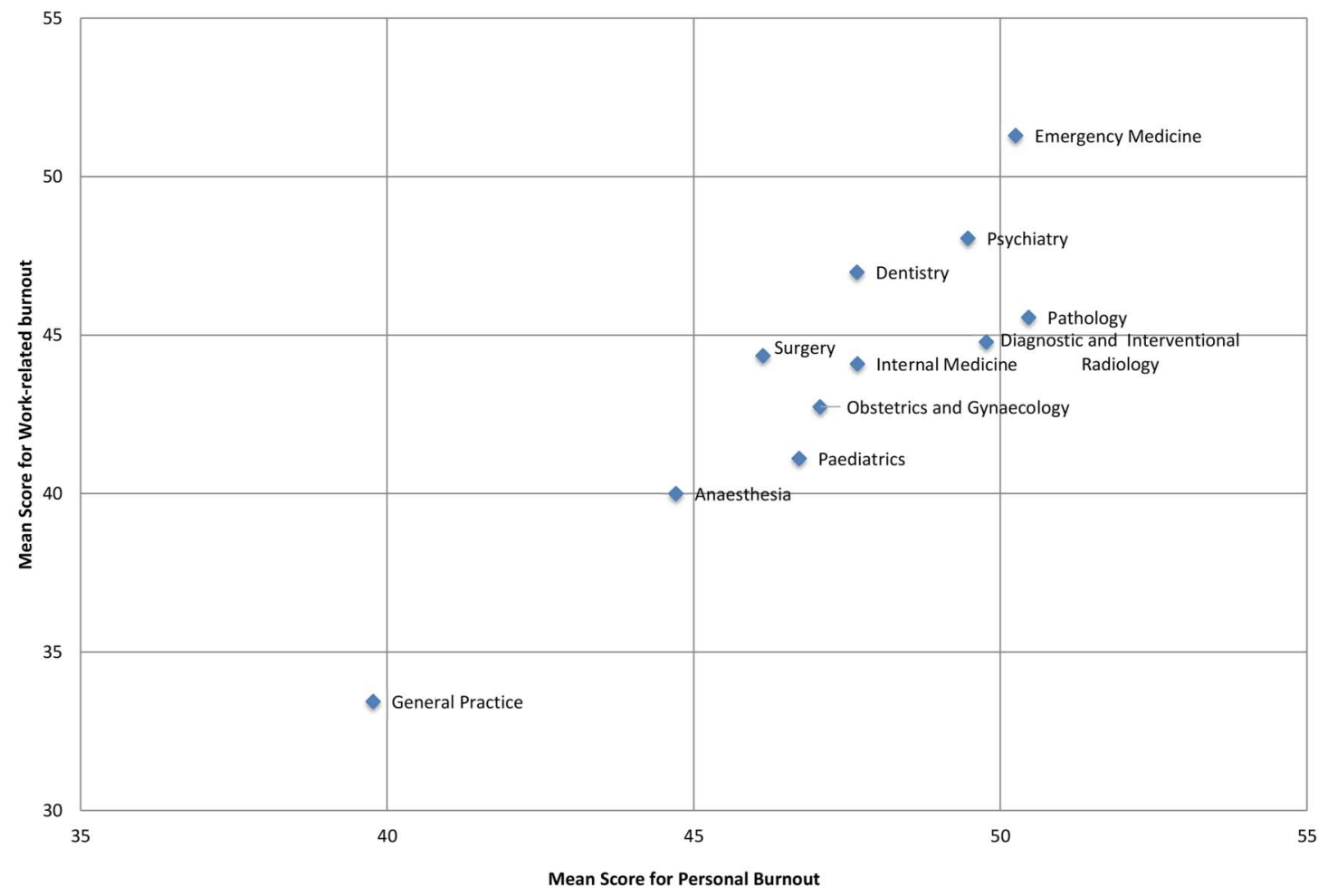

Figure 2 Mean work-related and personal burnout scores by medical specialty. 


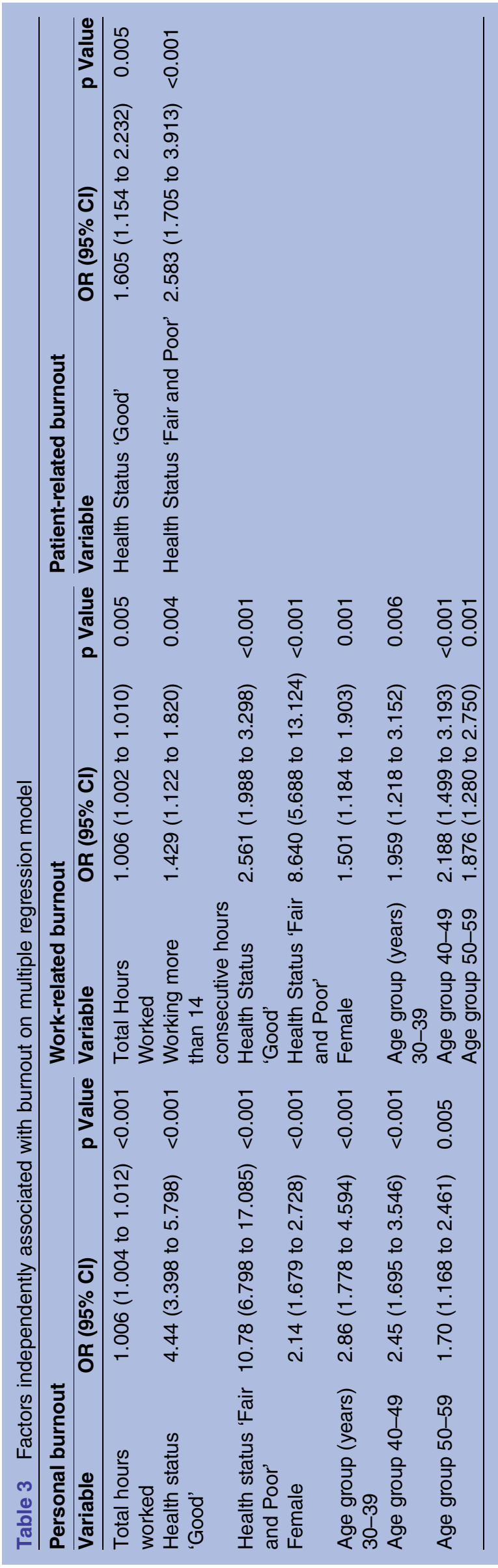

enquire about the most frustrating part ie, mediocre, intransigent management and under-resourcing”.

\section{DISCUSSION}

To the best of our knowledge, this study is the first to assess levels of burnout among senior doctors and dentists working in New Zealand's public health system. This is also the first study to use the CBI in this cross-specialty cohort of medical professionals. The results suggest that burnout is prevalent across New Zealand's senior medical workforce with particularly high scores for individual physical and psychological exhaustion across all DHBs. Compared with other studies using the CBI, the findings from this research suggest the levels of personal and work-related burnout in this cohort are significantly higher than what is often found in human service workers ${ }^{18}$ although the patient-related burnout scores are similar to those found in other studies and are in some instances lower. ${ }^{2} 21$ The scores for personal and patient-related burnout are very similar to those found in study of German physicians which also had a similar sample size. ${ }^{12}$ Our findings suggest that being a woman, aged between 30 and 39 years, having poor self-rated health status, and having worked for 5-14 years in New Zealand are all factors associated with the highest levels of burnout. Working in emergency medicine and psychiatry is also associated with very high work-burnout and those working in psychiatry and dentistry had high patient-related burnout scores.

The themes illustrated by the qualitative data provide insight into the issues to which respondents attribute their concerns. There is a clear emphasis on issues such as under-resourcing, workload, poor management and short staffing. The emphasis on working conditions in the qualitative comments suggests that work and working conditions are perceived as significant contributing factors to overall feelings of exhaustion and fatigue.

Notable in the findings is the strong correlation between burnout and gender, with women surveyed significantly more likely to score as burnt-out across personal and work-related measures of burnout than their male counterparts. Being a woman also significantly increased the odds of experiencing personal and workrelated burnout by 2.1 and 2.6 times, respectively. Analysis of the qualitative comments found women were more likely to note issues associated with having young children in their comments than their male counterparts. This was particularly so for comments cross-cut by gender and age group. For example, one woman in the subgroup of 30-39 year olds who left comments noted that "I have a small toddler at home and am currently pregnant. Not sure what is more exhausting-work or home!". These findings echo other recent studies which found that women had significantly higher personal burnout scores than their male counterparts. ${ }^{22-24}$

The higher mean rates and prevalence of burnout for both men and women aged between 30 and 39 years is 
Table 4 Macro themes with subthemes and illustrative comments

\begin{tabular}{ll}
\hline Macro theme & Subtheme \\
\hline Interpersonal & Recognition and support \\
relationships & Ability to influence and control \\
& Interactions with patients \\
& Interactions with management
\end{tabular}

Illustrative comments

I am the nominated clinical leader for our service. Despite this, my

ability to influence any aspect of the operation of our service is severely limited. It is this constant lack of control-the knowledge that things could be much better than they actually are but the inability to make the necessary changes - that is so sapping for me. Constantly delivering low value activities is demoralising. The lack of ability to engage effectively with middle and senior management to progress the implementation of quite modest changes in working practices and the lack of support from medical colleagues for a change in approach within our unit are together profoundly depressing. It does make me think quite often that I would be better off elsewhere.

$\begin{array}{ll}\text { Resourcing } & \text { Staffing levels } \\ \text { Administrative support } \\ \text { IT issues } \\ \text { Physical environment eg, } \\ \text { office space }\end{array}$

Workload issues Hours of work Intensity of work On-call and shiftwork Ability to access and impact of leave

Part-time vs full-time work

Impact of dependents Family time Importance of exercise, mindfulness and leave

Work/life balance
Targets

Issues with systems and structures

Political pressures
The staff shortage in our department is so chronic that a 'normal' weekly roster is almost unheard of and most weeks I am covering more than just my given area. We are all asked on a regular basis to do extra hours to cover other people's leave. It has been going on for so long that it has become the new 'normal' and it is only when I have an occasional week where I only have to do my set job that I realise how busy and demanding the job constantly is.

There is an emphasis on counting 'face-to-face' contacts from our management which ignores the quality/intensity/duration of clinical encounters. This values locum style superficial churning of cases, as that approach generates good statistics. This is very discouraging for clinicians that maintain a specialist standard, as there is no recognition of the quality of clinical work-which in psychiatry can be very draining, in terms of time and emotions. There seems to be no way of maintaining standards and increasing throughput, so the pressure to do a worse job is demoralising. Of course, burnt out psychiatrists become detached and disengaged, and therefore more able to superficially churn through high frequency, low quality clinics. So locums and burnt out psychiatrists generate good statistics-and the most valued outcomes are statistics. All of this occurs within the hours of work. Rather than routinely staying late, non-clinical time goes. This isn't therefore captured by my hours of work.

For me, the hardest part of being a female in the medical workforce is resisting the notion that we should work in our own time to keep up with our paperwork. Family and childcare commitments mean that I can't work from home in my own time and, quite frankly, I won't allow myself to fall into that habit. This is something that some of my more 'senior/old school' colleagues don't seem to agree with or understand. I put all my energy into my work day just to keep up with the onerous amount of paperwork that comes with my particular role, and even so, never seem to be quite on top of things. In my department, we have no scheduled non-patient or non-clinical time either, so we rely entirely on having a 'quiet' day clinically to find some time to catch up. The added stress of always being 'one step behind' has contributed enormously to my feelings of not being to cope with this work, and enjoying my work less now than I used to.

I left the UK because of frustration with the stupid healthcare system. I came to NZ as the system here was much better. The idiocy has followed me. I have no problems with patients or my job. I have problems with targets, poor equipment and mindless regulation. We are being pressurised to breaking point to increase throughput with no measurement of quality of kindness or thought
The findings from the multiple regression analysis suggest a clear drop-off in burnout for those aged over 60 years. There are several possible explanations. First, there is likely to be a selection effect, with those worst younger specialists in this cohort will be early on in their specialist career and may experience specific stressors as a consequence ${ }^{27}$ although this was not probed directly. 
affected having taken early retirement or, possibly, experiencing severe illness or premature death. A second, related issue is that those who remain in employment will have either been selected on the basis of their resilience or have developed coping mechanisms over the course of their career. One respondent referenced the importance of experience as 'buffering' them from the risk of burnout: "I am close to retirement and have lots of experience to buffer the clinical stresses and management frustrations. For me this survey 15 or 20 years ago would have elicited very different responses when my stresses and frustrations were much higher...". A third possibility is selective response to the survey. It is possible that the physicians aged over 60 years who participated in this study may be a resultant pool of specialists who are better able to tolerate challenging conditions at work and resist fatigue and exhaustion; ${ }^{28}$ analysis of the FTE and hours of work data for those aged over 60 years for example, did not suggest that this cohort had lower average FTE or weekly hours of work than the overall average even though many physicians are reducing their hours of work when they reach this age group.

The findings from this study confirm trends in the existing literature for certain medical specialties to experience higher rates of work-related and personal burnout than others. ${ }^{29-33}$ Analysis of the comments left by emergency medicine specialists, for example, found emphasis on the tiring and burdensome realities of shift work and on-call duties as well as reference to the intense workloads of the public hospital's emergency department. As one respondent noted: "I love emergency medicine (but) feel frequently oppressed and worn out by the conditions in which we practice it, with volume overload, staff shortages, access block (and) lack of resources". Comments left by psychiatrists highlighted the challenges of dealing with a growing incidence of mental illness and the concurrent pressure to treat greater numbers of patients without an increase in resources, echoing themes in the wider literature. ${ }^{34}$ As the comment cited in table 4 suggests, psychiatrists suffering from burnout may score well against New Zealand's Ministry of Health targets, because "burnt out psychiatrists become detached and disengaged, and therefore better able to superficially churn through high frequency, low quality clinics. So locums and burnt out psychiatrists generate good statistics-and the most valued outcomes are statistics".

The significant correlations between burnout and specific medical specialisations suggest that for certain medical specialties, there are major pressures that are negatively affecting morale. Again it is necessary to consider selection, as it is plausible that those seeking a career in emergency medicine, for example, are those who feel best able to cope with high intensity, stressful work. If this is the case, then the findings are even more alarming. Given the strong connections noted in the literature between burnout, patient outcomes and likelihood of staff turnover, these trends warrant further research.

Burnout scores increased concurrently with increasing hours worked per week, consistent with the findings in other studies using the $\mathrm{CBI}^{2}$ and the MBI. ${ }^{35}$ Hours of work were also associated independently with the likelihood of personal and work-related burnout. The 61.5 average hours of work across the week found in this study was consistent with the average weekly hours for New Zealand doctors reported in other research. ${ }^{14}$ The emphasis in the qualitative comments on issues associated with working shifts and on-call duties suggest that these factors may confer a higher risk of burnout. $^{36}$

In the current study, slightly less than half the respondents $(46 \%)$ had a period of rest of $<10$ hours between work and the same percentage had worked for more than 14 consecutive hours. Working more than 14 consecutive hours was strongly associated with personal and work-related burnout measures, in terms of the mean scores and the prevalence of burnout. This was also a factor independently associated with work-related burnout in the regression analysis. This may reflect the impact such working hours may have on available time for sleep. ${ }^{5}$ The relationship between burnout, hours of work and disturbed sleep, particularly in the context of shift work and night call duties, common in this workforce, should be researched further.

\section{STRENGTHS AND LIMITATIONS OF THIS STUDY}

A key strength of this study pertains to the multicentre, cross specialty focus. Unlike many other studies which either focus on levels of burnout in a single centre or within a single specialty across different places of work, this study provides insight into the levels of burnout experienced at a single point of time by senior doctors and dentists of many specialties working in all DHBs in New Zealand. The use of a validated instrument with a high internal consistency, having a large number of responses (although a moderate response rate) and attaining a representative spread of responses across gender and DHBs further adds to the power of this study. An additional strength of this study is the consideration of the results alongside the qualitative analysis of the comments left by respondents. While many of the ideas raised in the comments cannot be objectively substantiated, the themes in the comments proved a useful source of contextual information and revealed a great deal concerning individual's perceptions of the main attributional schemas contributing to their feelings of stress, anxiety and exhaustion.

There are, nonetheless, a number of limitations of this research which require consideration. The reliance of self-reporting, particularly for the hours of work questions, may have resulted in some under or over reporting of the data. It must also be questioned whether the mode of delivery, in this instance, an online survey, may 
have shaped the responses and the patterns of who responded. While the $40 \%$ response rate is reasonable, response bias may be present; it is possible that those who have experienced burnout in the past may have been more interested in participating than those who have not but equally, it is possible that those with current high levels of burnout may have felt too exhausted to participate in the study. ${ }^{18} 37$ A related limitation of the study is the low number of responses in certain categories; for example, there were only three respondents in the 20-29 age group although this reflects the Medical Council of New Zealand's (MCNZ) workforce survey which recorded no specialists in this age group and only 28 medical officers. ${ }^{38}$

It is also worth considering the extent to which the results are shaped by selective pressures acting over individuals' employment trajectories. Thus, it is plausible that certain specialities, such as emergency medicine, may attract those who have greater degrees of resilience to burnout (or alternatively, have less insight into the risk of experiencing it). It is also likely that there will be a process of attrition as those worst affected leave the workforce early. Another limitation pertains to the difficulties in establishing causality and directionality between the burnout scores and significant correlating factors. As a cross-sectional survey, the associations observed cannot be interpreted as causal but they certainly warrant further examination in future studies. Where relevant, this has been noted in the analysis.

Finally, and with the benefit of hindsight, the survey did not adequately capture some key issues. Thus, as noted by several respondents, the CBI was not able to probe directly feelings of stress and exhaustion that may be attributed to management-related issues even though this emerged as a key concern in the qualitative analysis. The issue of dependents was also not queried explicitly and future research should include the number and age of dependents as a variable against which to consider the findings. It should also explore working conditions and workload factors in this medical workforce in more detail, for example, by surveys using validated tools such as the effort-reward imbalance questionnaire.

Notwithstanding these limitations, these results provide insight into the psychosocial health of the senior medical workforce in New Zealand and offer a model that could, subject to the adaptations noted in the previous paragraph, be applied in other countries. The high overall level of burnout suggested by this research is concerning both the health of this workforce and its implications on the quality of patient care. The results indicate a need for a comprehensive response, which could be coupled with specific interventions targeted towards the subsections of this medical cohort who appear to be at greatest risk. ${ }^{39}$

Contributors The report was written by CNLC, statistical analysis was performed by CMAF and contributions were received from MB and MMcK. All authors edited and revised the final submission and signed off on the final version.
Funding This research received no specific grant from any funding agency in the public, commercial or not-for-profit sectors.

Competing interests None declared.

Provenance and peer review Not commissioned; externally peer reviewed.

Data sharing statement No additional data are available.

Open Access This is an Open Access article distributed in accordance with the Creative Commons Attribution Non Commercial (CC BY-NC 4.0) license, which permits others to distribute, remix, adapt, build upon this work noncommercially, and license their derivative works on different terms, provided the original work is properly cited and the use is non-commercial. See: http:// creativecommons.org/licenses/by-nc/4.0/

\section{REFERENCES}

1. Shanafelt TD, Boone S, Tan L, et al. Burnout and satisfaction with work-life balance among US physicians relative to the general US population. Arch Intern Med 2012;172:1377-85.

2. Chou LP, Li CY, Hu SC. Job stress and burnout in hospital employees: comparisons of different medical professions in a regional hospital in Taiwan. BMJ Open 2014;4:e004185.

3. Thun S, Fridner A, Minucci D, et al. Sickness present with signs of burnout: the relationship between burnout and sickness presenteeism among university hospital physicians in four European countries. Scandinavian Psychologist 2014;1:1-22.

4. Amoafo E, Hanbali N, Patel A, et al. What are the significant factors associated with burnout in doctors? Occup Med (Lond) 2015;65:117-21.

5. Ekstedt M, Söderstrom M, Akerstedt T, et al. Disturbed sleep and fatigue in occupational burnout. Scand J Work Environ Health 2006;32:121-31.

6. Shirom A, Nirel N, Vinokur AD. Work hours and caseload as predictors of physician burnout: the mediating effects by perceived workload and by autonomy. Appl Psychol 2010;59:539-65.

7. Borritz M, Christensen KB, Bultmann U, et al. Impact of burnout and psychosocial work characteristics on future long-term sickness absence. Prospective results of the Danish PUMA Study among human service workers. J Occup Environ Med 2010;52: 964-70.

8. Kakiashvili T, Leszek J, Rutkowski K. The medical perspective on burnout. Int J Occup Med Environ Health 2013;26:401-12.

9. Bianchi R. Occupational and non-occupational strains should be concomitantly considered in research on burnout, organizational commitment, and turnover intention. Int J Nurs Stud 2016;53: 403-4.

10. Tziner AE, Rabenu E, Radomski R, et al. Work stress and turnover intentions among hospital physicians: the mediating role of burnout and work satisfaction. J Work Organ Psychol 2015;31:207-13.

11. Firth-Cozens J, Greenhalgh J. Doctors' perceptions of the links between stress and lowered clinical care. Soc Sci Med 1997;44:1017-22.

12. Klein J, Grosse Frie K, Blum K, et al. Burnout and perceived quality of care among German clinicians in surgery. Int J Qual Healthcare 2010;22:525-30.

13. Shirom A, Nirel N, Vinokur AD. Overload, autonomy, and burnout as predictors of physicians' quality of care. J Occup Health Psychol 2006;11:328-42.

14. Chen $\mathrm{KY}$, Yang $\mathrm{CM}$, Lien $\mathrm{CH}$, et al. Burnout, job satisfaction, and medical malpractice among physicians. Int J Med Sci 2013;10:1471-8.

15. Fahrenkopf AM, Sectish TC, Barger LK, et al. Rates of medication errors among depressed and burnt out residents: prospective cohort study. BMJ 2008;336:488-91.

16. Kristensen TS, Borritz M, Villadsen E, et al. The Copenhagen Burnout Inventory: a new tool for the assessment of burnout. Work and Stress 2005;19:192-207.

17. Schaufeli WB, Taris TW. The conceptualization and measurement of burnout: common ground and worlds apart. Work and Stress 2005;19:256-62.

18. Borritz M, Rugulies R, Bjorner JB, et al. Burnout among employees in human service work: design and baseline findings of the PUMA study. Scand J Public Health 2006;34:49-58.

19. AMA. National Code of practice-hours of work, shiftwork and rostering for hospital doctors. Kingston, Australia: The Australian Medical Association, 2005.

20. Charmaz K. Grounded theory as an emergent method. In: Hesse-Biber SN, Leavy P, eds. Handbook of emergent methods. New York: The Guilford Press, 2008:155-72. 
21. D'Souza F, Egan SJ, Rees CS. The relationship between perfectionism, stress and burnout in clinical psychologists. Behaviour Change 2011;28:17-28.

22. Jacobs LM, Nawaz MK, Hood JL, et al. Burnout among workers in a pediatric healthcare system. Workplace Health Saf 2012;60:335-44.

23. Parr JM, Pinto N, Hanson M, et al. Medical graduates, tertiary hospitals, and burnout: a longitudinal cohort study. Ochsner $J$ 2016;16:22-6.

24. Cheng Y, Chen IS, Chen CJ, et al. The influence of age on the distribution of self-rated health, burnout and their associations with psychosocial work conditions. J Psychosom Res 2013;74:213-20.

25. Kamal $\mathrm{AH}$, Bull JH, Wolf SP, et al. Prevalence and predictors of burnout among hospice and palliative care clinicians in the U.S. $J$ Pain Symptom Manage 2016;51:690-6.

26. Norlund S, Reuterwall C, Höög J, et al. Burnout, working conditions and gender-results from the northern Sweden MONICA Study. BMC Public Health 2010;10:326.

27. Robinson G, Morreau J, Leighton M, et al. New hospital consultant: surviving a difficult period. N Z Med J 2007;120:U2662.

28. Dyrbye LN, Varkey $P$, Boone SL, et al. Physician satisfaction and burnout at different career stages. Mayo Clin Proc 2013;88:1358-67.

29. Estryn-Behar M, Doppia MA, Guetarni K, et al. Emergency physicians accumulate more stress factors than other physicians-results from the French SESMAT study. Emerg Med J 2011;28:397-410.

30. Fothergill A, Edwards D, Burnard P. Stress, burnout, coping and stress management in psychiatrists: findings from a systematic review. Int J Soc Psychiatry 2004;50:54-65.
31. Howlett M, Doody K, Murray J, et al. Burnout in emergency department healthcare professionals is associated with coping style: a cross-sectional survey. Emerg Med J 2015;32:722-7.

32. Kumar S, Sinha P, Dutu G. Being satisfied at work does affect burnout among psychiatrists: a national follow-up study from New Zealand. Int J Soc Psychiatry 2013;59:460-7.

33. Lu DW, Dresden S, McCloskey C, et al. Impact of burnout on self-reported patient care among emergency physicians. West J Emerg Med 2015;16:996-1001.

34. Rössler W. Stress, burnout, and job dissatisfaction in mental health workers. Eur Arch Psychiatry Clin Neurosci 2012;262(Suppl 2): S65-9.

35. Surgenor LJ, Spearing RL, Horn J, et al. Burnout in hospital-based medical consultants in the New Zealand public health system. $N$ Z Med J 2009;122:11-18.

36. Kuhn G, Goldberg R, Compton S. Tolerance for uncertainty, burnout, and satisfaction with the career of emergency medicine. Ann Emerg Med 2009;54:106-13 e6.

37. Roberts DL, Shanafelt TD, Dyrbye LN, et al. A national comparison of burnout and work-life balance among internal medicine hospitalists and outpatient general internists. J Hosp Med 2014;9:176-81.

38. MCNZ. The New Zealand medical workforce in 2013 and 2014. Wellington, New Zealand: Medical Council of New Zealand, 2016.

39. West CP, Dyrbye LN, Erwin PJ, et al. Interventions to prevent and reduce physician burnout: a systematic review and meta-analysis. Lancet 2016;3882272-81. 